\title{
Cytology of Metastatic Renal Medullary Carcinoma in Pleural Effusion: A Study of Two Cases
}

\author{
Carla L. Ellis, M.D., ${ }^{1}$ Frances Burroughs, S.C.T. (A.S.C.P.), ${ }^{1}$ \\ Claire W. Michael, M.D., ${ }^{2}$ and Qing Kay Li, M.D., Ph.D. ${ }^{+{ }^{*}}$
}

Renal medullary carcinoma (RMC) is a rare and aggressive malignant epithelial neoplasm of the kidney. It almost exclusively affects children and young adults with a sickle cell trait or sickle cell disease. The majority of RMC patients present with widely disseminated disease at the time of diagnosis. Herein, we report two cases of young African-American patients with history of sickle cell trait, hematuria and renal mass, who present with malignant right pleural effusions. The cytology of pleural effusion reveals predominantly clusters and individual tumor cells. The tumor cells show high nuclear to cytoplasmic (NC) ratios and large nuclei with nuclear pleomorphism, nuclear grooves, and prominent single or multiple nucleoli. The cytoplasm is dense with a vacuolated and two-tone appearance. Surgical specimens of renal mass and lymph node show features of RMC.

Metastatic RMC to the serous cavity is rare and may present a diagnostic dilemma since it may mimic a poorly differentiated adenocarcinoma or other high-grade malignant neoplasms. $R M C$ should be considered in the differential diagnosis in young patients with a renal mass, particularly in those with history of sickle cell trait or sickle cell disease. Diagn. Cytopathol. 2009;37:843-848. @ 2009 Wiley-Liss, Inc.

Key Words: cytology; metastatic renal medullary carcinoma; pleural effusion

Renal medullary carcinoma (RMC) is a highly aggressive malignant epithelial neoplasm of the kidney. Since the first description by Davis CJ in 1995, more than one hundred cases have been reported in the literature. ${ }^{1-10}$ It almost exclusively affects children and young adults with

\footnotetext{
${ }^{1}$ Division of Cytopathology, Department of Pathology, The Johns Hopkins Hospital, Baltimore, Maryland

${ }^{2}$ Department of Pathology, The University of Michigan Hospital, Ann Arbor, Michigan

*Correspondence to: Qing Kay Li, M.D., Ph.D., Division of Cytopathology, Department of Pathology, The Johns Hopkins Hospital, 600 N.

Wolfe Street, Baltimore, MD 21287. E-mail: qli23@jhmi.edu

Received 15 February 2009; Accepted 20 April 2009

DOI 10.1002/dc.21111

Published online 12 June 2009 in Wiley InterScience (www.interscience. wiley.com).
}

a history of sickle cell trait or sickle cell disease. The average age of patients is 21 years, and the male to female ratio is 2.2:1.0. Clinically, the most common symptoms are hematuria, abdominal pain, weight loss and renal mass. The majority of RMC patients present with widely disseminated disease at the time of diagnosis.

The origin of RMC is still unknown, but it has been suggested that RMC may arise from the calyceal epithelium of the renal pelvis or near the renal papillae. ${ }^{1}$ Histologically, the most notable features of RMC are reticular and compact adenoid cystic growth patterns with focal solid area. ${ }^{1,2,6,7}$ The cells are high-grade malignant cells with prominent nucleoli. In solid area, the cells may have rhabdoid or plasmacytoid features. Neutrophil infiltration and microabscess formation can be found in the desmoplastic stroma. ${ }^{1,2,6,7}$ RMC may present as a diagnostic dilemma, particularly when it metastasizes outside of the kidney.

Herein, we report two cases of metastatic RMC presenting with right sided malignant pleural effusions. The cytological features of RMC in the exfoliative specimens are readily identified as malignant effusion; however, they have some features that overlap with other high-grade malignant neoplasms, such as adenocarcinoma, renal cell carcinoma, urothelial cell carcinoma, collecting duct carcinoma and few others. The purpose of this work is to summarize the cytological findings of metastatic RMC in the pleural effusion and to discuss relevant features of the differential diagnoses.

\section{Materials and Methods}

Two cytospins were prepared from each pleural effusion specimen. These were fixed in 95\% ethanol and stained by Papanicolaou method. Cell blocks were also prepared, fixed in formalin and processed in the histology laboratory according to standard protocols. The sections of the cell block were stained with hematoxylin and eosin (H\&E) method. 
Table I. Summary of Antibodies and Manufacturers

\begin{tabular}{lcccc}
\hline Antibodies & Type & Source & Dilution & Antigen retrieval \\
\hline AE1/AE3 & Monoclonal & Ventana & None & None \\
CAM 5.2 & Monoclonal & Ventana & Prediluted & CC1 \\
Vimentin & Monoclonal & Ventana & $1: 20$ & CC1 \\
EMA & Monoclonal & Ventana & Prediluted & None \\
mCEA & Monoclonal & Ventana & Prediluted & CC1 \\
CK7 & Monoclonal & Ventana & $1: 500$ & None \\
CK20 & Monoclonal & Ventana & $1: 20$ & CC1 \\
K903 & Monoclonal & Ventana & $1: 20$ & None \\
Calretinin & Polyoclonal & Ventana & $1: 20$ & CC1 \\
TTF-1 & Monoclonal & Ventana & $1: 500$ & CC1 \\
RCC & Monoclonal & Ventana & $1: 10$ & Pronase \\
CD10 & Monoclonal & Ventana & $1: 20$ & CC1 \\
Desmin & Monoclonal & Dako & $1: 100$ & CC1 \\
Myogenin & Monoclonal & Ventana & Prediluted & None \\
\hline
\end{tabular}

CC1, cell conditioning solution; TTF-1, thyroid transcription factor-1; RCC, renal cell carcinoma; EMA, epithelial membrane antigen; mCEA, monoclonal carcinoembryonic antigen.

Immunohistochemical studies were performed on the cell block material. The sections were cut at four micron thickness and deparaffinized before incubation with primary antibodies. Heat antigen retrieval at $70^{\circ} \mathrm{C}$ for 40 minutes was also used to enhance the signal detection. The immunohistochemistry was performed by using a Dako autostrainer. The dilutions of primary antibodies were used according to manufacturer's suggestions and standard protocols. The information of primary antibodies was summarized in Table I.

\section{Results}

\section{Clinical Findings}

Case 1. A 26-year-old African-American male with a history of sickle cell trait presented with cough, fevers, shortness of breath, and was clinically suspected to have an upper respiratory tract infection. Chest X-ray showed infiltrates of the right middle and lower lobes. The patient was treated symptomatically, however, the symptoms persisted; and the patient subsequently developed a right pleural effusion, weight loss and hematuria. A computerized tomography (CT) scan and positron emission tomography-computed tomography (PET-CT) demonstrated a large $(7.8 \times 6.2 \times 6.2 \mathrm{~cm})$ right renal mass and multiple lesions in both lobes of the lungs, the liver and the adrenal glands. The patient also had an extensive retroperitoneal lymphadenopathy. The pleural effusion was sent for cytological examination. The patient also underwent resection of his renal mass and biopsy of the lung masses. A diagnosis of RMC was made. Chemotherapy was initiated. Despite aggressive treatment, the patient continued to deteriorate and died 4 months after the diagnosis.

Case 2. A 13-year-old African-American female with a history of sickle cell trait presented with shortness of breath, back pain for several months, and hematuria for one month. The CT scan showed a large $(10 \times 8.5 \times$
$8 \mathrm{~cm}$ ) right renal mass with retroperitoneal extension and invasion of the inferior vena cava, multiple lung lesions, a right sided pleural effusion and an enlarged supraclavicular lymph node. The pleural effusion was sent for cytological examination. The patient underwent biopsy of the right supraclavicular lymph node. The diagnosis of metastatic RMC was made. Chemotherapy was initiated. The patient was discharged after chemotherapy, but was readmitted a few weeks later with fever, vomiting and diarrhea. The patient's condition continued to deteriorate. She died 3 months after the diagnosis.

\section{Pathological Findings}

Cytological findings. Cytological examination of the effusion specimens revealed numerous malignant cells in a background of reactive mesothelial cells and mixed inflammatory cells (Figs. C-1 and C-2). In both of our cases, tumor cells were arranged predominantly in tight clusters (Fig. C-1), two-dimensional groups and scattered single cells (Fig. C-2), however, no true papillary fragments with fibrovascular cores were identified. The tumor cells had an epithelial appearance with high NC ratio and large pleomorphic nuclei. The nuclei were often eccentrically located with irregular nuclear membranes, and one or several prominent nucleoli. The chromatin was finely granular to vesicular in texture. The cytoplasm of the tumor cells was dense and had two-tone appearance, and distinct cell border. Many of the cells had vacuolated cytoplasm; and, in some instances, they indented the nuclei.

Histological findings. The surgical specimen of renal mass of case 1 showed that the tumor was predominantly raised from renal medulla. The tumor showed a compact adenoid cystic and solid growth patterns with areas of cystic degeneration (Figs. C-3A and B). The cells had large hyperchromatic nuclei, irregular nuclear membranes, fine to coarse chromatin, and one prominent or several smaller nucleoli. Extensive necrosis and desmoplastic stromal reaction were present. Foci of neutrophil infiltration and microabscess formation were present. Lymphatic and blood vessel invasion were identified. Lymphoid infiltration was present at the periphery of the tumor. The biopsy specimen of the right supraclavicular lymph node of case 2 showed similar morphology to that of the renal mass (Figs. C-3C and D).

Ancillary studies. Immunohistochemical studies were performed on cell blocks. The tumor cells were diffusely positive for cytokeratin AE1/AE3 and Cam5.2, and focally positive for epithelial membrane antigen (EMA) and CK7 in both cases. In one case, tumor cells were focally positive for vimentin, K903, monoclonal carcinoembryonic antigen (mCEA). Tumor cells were negative for calretinin, TTF-1, CK20, renal cell carcinoma (RCC), CD10, and Ulex in both cases. Tumor cells were also negative for desmin and myogenin. The selective immune results, such as Cam5.2, 


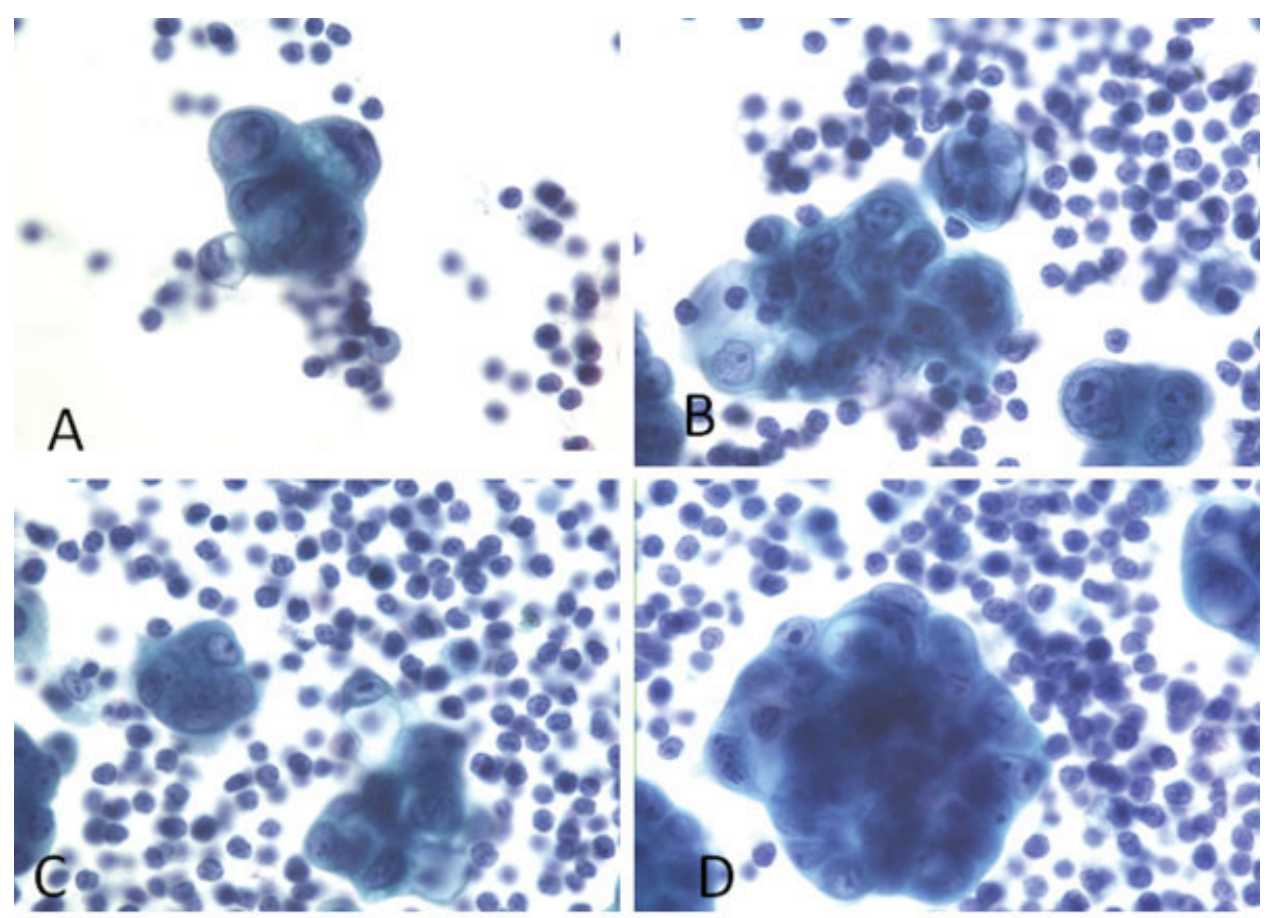

Fig. C-1
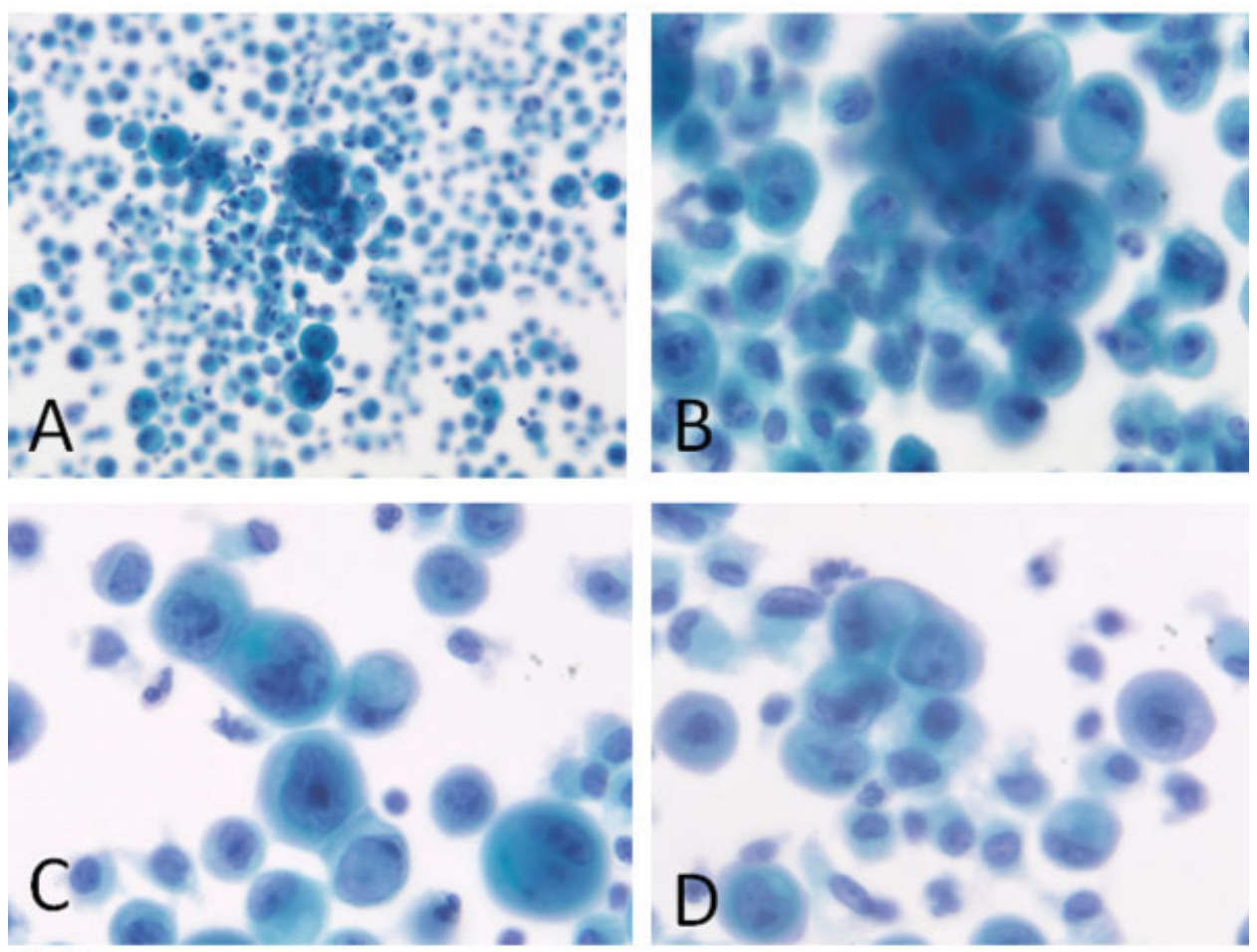

Fig. C-2

Figs. C-1-C-2. Fig. C-1. Cytospin specimen of pleural effusion (Papanicolaou stain, $\times 100$ ). The tumor cells are arranged predominantly in tight clusters. No true papillary fragments with fibrovascular cores are present. The tumor cells have large hyperchromatic nuclei, irregular nuclear membranes, fine to coarse chromatin, and one or several smaller prominent nucleoli. The cytoplasm contains vacuoles that displace or indent the nucleus. Fig. C-2. Cytospin specimen of pleural effusion (Papanicolaou stain, A $\times 40 ; \mathbf{B}, \mathbf{C}$, and $\mathbf{D} \times 100$ ). Some area of the tumor cells are arranged in two-dimensional groups and scattered single cells. In addition to hyperchromatic nuclei and nuclear atypia, the cytoplasm of the tumor cells also has a two-tone appearance and distinct border. 

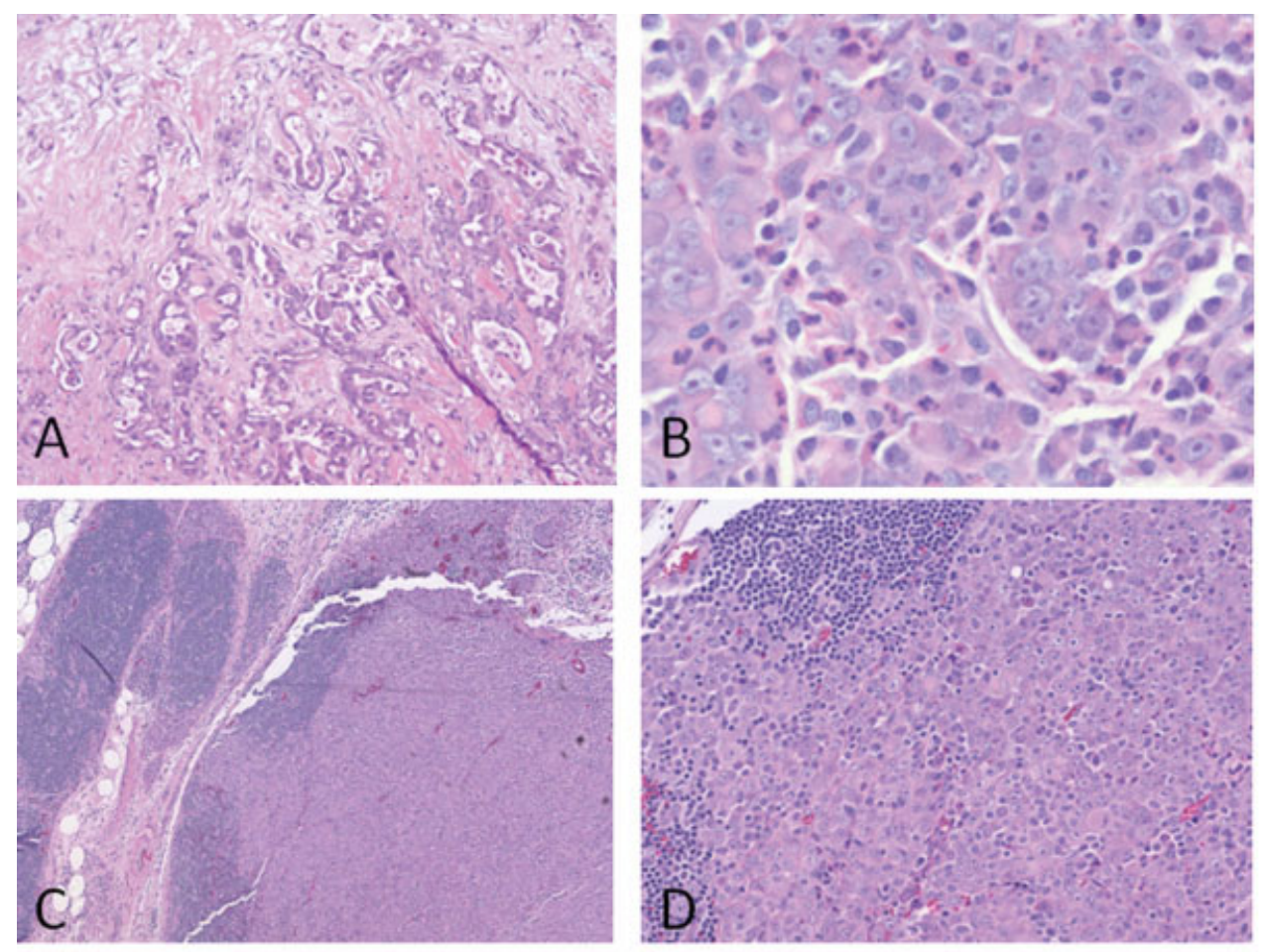

Fig. C-3
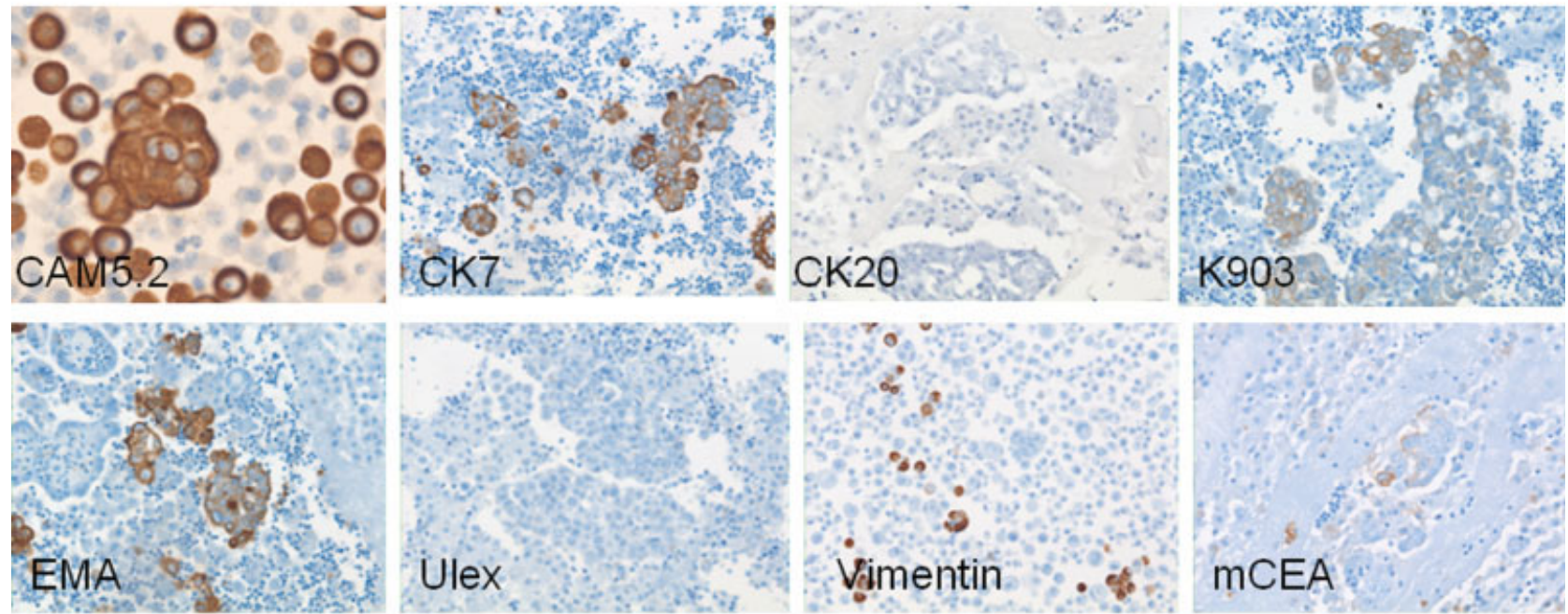

Fig. C-4

Figs. C-3-C-4. Fig. C-3. The surgical specimen of the renal mass of case 1 (A and $\mathbf{B}, \mathrm{H} \& \mathrm{E}$ stain, $\times 10$ and $\times 20$ ). The tumor shows a compact adenoid cystic and solid growth patterns (A). The cells have large hyperchromatic nuclei, irregular nuclear membranes, fine to coarse chromatin, and one prominent or several smaller nucleoli. Tumor necrosis and desmoplastic stromal reaction are present. Foci of neutrophilic infiltrates and microabscesses formation are present (B). The biopsy specimen of the right supraclavicular lymph node of case 2 shows similar morphology to that of the renal mass $(\mathbf{C}$ and D, H\&E stain, $\times 10$ and $\times 20)$. Fig. C-4. Immunohistochemical studies $(\times 20)$. The tumor cells are positive for cytokeratin Cam5.2 $(\times 40)$, focally positive for CK7, K903, EMA, mCEA, vimentin; and negative for CK20 and Ulex.

CK7, CK20, K903, EMA, mCEA, Ulex, and vimentin, were shown in Figure C-4.

\section{Discussion}

The cytological findings of RMC have been reported in the urine,${ }^{11}$ in renal pelvic washings ${ }^{12}$ and in fine-needle aspiration of renal masses. ${ }^{12,13}$ In both the exfoliative and FNA specimens, the tumor cells predominantly form loosely cohesive or two-dimensional clusters, and single cells. In urine and pelvic washings, the tumor cells reveal a high NC ratio, marked nuclear pleomorphism, irregular nuclear membranes and prominent nucleoli. The cyto- 
plasm is dense and granular with a sharply defined cytoplasmic border. The cytoplasm of the tumor cells also contains multiple small vacuoles or a single large vacuole that displaces and indents the nucleus. ${ }^{11,12}$ FNA cytology of RMC reveals similar features such as nuclear pleomorphism, eccentric and irregular nuclei, prominent nucleoli and vacuolated cytoplasm. ${ }^{13}$ None of these authors has found true papillary configurations in the cytological specimen.

Interestingly, both of our patients have right side pleural effusions, which are consistent with the observation that the right kidney is involved three times more commonly than the left kidney in the series of 33 cases reported by Davis et al. ${ }^{1}$ In our cases, the cytological findings of the pleural effusions show similar features as those seen in urine and FNA specimens. Taken together, the most common findings from ours and others are large tumor cells with pleomorphic nuclei and prominent nucleoli, dense and vacuolated cytoplasm, and distinct cytoplasmic borders. Although the tumor cells form clusters, there are no true papillary configurations present.

The differential diagnoses of RMC in the pleural effusion are broad and include metastatic adenocarcinoma of lung, renal cell carcinoma, urothelial cell carcinoma, and collecting duct carcinoma. Adernocarcinoma of the lung usually occurs in elderly patients. In exfoliative cytology, adenocarcinoma may form three-dimensional tight clusters and acinar structures. Some of the tumor cells may have intracytoplasmic mucin. These features indicate glandular differentiation. $^{14}$ The nuclei of the tumor cells have coarse chromatin, irregular nuclear membrane and prominent nucleoli. The cytoplasm of the tumor cells is vesicular and lacy, and the cells do not have distinct cell borders. ${ }^{14}$ Immunohistochemical stains of tumor cells may be helpful and are usually positive for CK7 and TTF-1.

Both renal cell carcinoma and urothelial cell carcinoma have some overlapping features with RMC. ${ }^{1,2,6,7,12}$ However, the tumor cells of renal cell carcinoma form larger clusters. The cells have a low NC ratio, uniform nuclei and abundant clear or granular cytoplasm. The nuclei have fine chromatin and inconspicuous nucleoli. The presence of fibrillary basement membrane material is also a helpful feature for renal cell carcinoma. ${ }^{15}$ In urothelial cell carcinoma, the tumor cells form clusters and single cells. They have a large irregular hyperchromatic nuclei and dense cytoplasm. The nuclei are eccentrically located and with coarse chromatin. ${ }^{15}$ The presence of so-called "cercariform cells" is a clue for urothelial cell carcinoma. ${ }^{16}$ The "cercariform cells" are large tumor cells with a long cytoplasmic tails. Moreover, high-molecularweight cytokeratin K903 (34BE12) is positive in all urothelial cell carcinomas studied by Caraway et al. ${ }^{17}$ and is negative in all RMC studied by Swartz et al. ${ }^{7}$
The main differential diagnosis of RMC is collecting duct carcinoma, since it shares substantial morphological features with RMC. ${ }^{17}$ The tumor cells of collecting duct carcinoma show moderate pleomorphism and are arranged in two- or three-dimensional groups with papillary configurations. The nuclei are irregular with coarse chromatin and prominent nucleoli. The cytoplasm is vacuolated. Psammoma bodies have been reported to be present in four of the seven fluid specimen examined. ${ }^{17}$ Clinically, collecting duct carcinoma usually occurs in older patients without sickle cell trait, especially in males with a mean age of 53 year. ${ }^{18}$ To date, there are no specific immunomarkers to differentiate between RMC and collecting duct carcinoma. ${ }^{18}$ However, it has been reported that collecting duct carcinomas are typically positive for cytokeratin K903 and Ulex, ${ }^{18}$ whereas RMC are negative or focally positive for cytokeratin $\mathrm{K} 903^{2}$ and show variable staining for Ulex. ${ }^{7,12}$ Other immuno markers, such as EMA, CEA and vimentin, are reported to be variably expressed in $\mathrm{RMC}^{2}$ In our cases, the tumor cells are positive for cytokeratin AE1/AE3 and CAM5.2, negative or weakly, focally positive for K903, and negative for Ulex. The clinical history of sickle cell trait or disease is a key factor in distinguishing between these entities.

Davis CJ et al. has noted that some RMC had foci of poorly differentiated cells. These cells have dense eosinophilic cytoplasm and mimic those seen in rhabdoid tumor. ${ }^{1}$ In addition, some authors have reported that it is not uncommon for RMC to have a focal rhabdoid appearance. ${ }^{2,4,12,13}$ Although we do not find these features in our specimens, the differential diagnosis should also include rhabdoid tumor, particularly in children and young adults. Rhabdoid tumors usually present in the first 3 years of life, ${ }^{19,20}$ whereas RMC usually occurs in older patients, though the age range is broad. ${ }^{1,7}$ On cytology, rhabdoid tumors contain large pleomorphic atypical cells with dense cytoplasm or have features of small round cells. ${ }^{19,20}$ A tigroid background may be seen in some of the cases. The tumor cells may stain positive for smooth muscle actin, desmin and myogenin. ${ }^{20}$

Several genetic abnormalities have been suggested in RMC. Stahlschmidt J et al. described a patient with the bcr/abl rearrangement, as seen in chronic myelogenous leukemia. ${ }^{3}$ Avery RA et al. reports a patient with multiple abnormalities on chromosome 3 and $11 .^{5}$ Swartz MA et al. has found a patient with loss of chromosome 22 . $^{7}$ Yang XY et al. analyzes the gene expression profiles of two cases of RMC and compares the results with renal cell carcinoma and urothelial cell carcinoma. They have found that the molecular signature of RMC clusters closely with urothelial cell carcinoma of the renal pelvis, rather than renal cell carcinoma. ${ }^{21}$ Recently, it has been reported that loss of INI1 expression indicates aggressive behavior in RMC. ${ }^{22}$ All these studies indicate the com- 


\section{ELLIS ET AL.}

plexity of genetic abnormalities of RMC. Further studies are needed to determine whether these findings have clinical significance.

In summary, RMC has features of high-grade carcinoma in the pleural effusion specimen, but may not be readily recognized as renal in origin. The cytological features include large tumor cells with distinct cell borders. RMC should be considered in the differential diagnosis in young patients with renal mass, particularly in those with history of sickle cell trait or sickle cell disease.

\section{References}

1. Davis CJ, Jr, Mostofi FK, Sesterhann IA. Renal medullary carcinoma: The seventh sickle cell nephropathy. Am J Surg Pathol 1995;19:1-11.

2. Watanabe IC, Billis A, Guimaraes MS, et al. Renal medullary carcinoma: Report of seven cases from Brazil. Mod Pathol 2007;20:914-920.

3. Stahlschmidt J, Cullinane C, Roberts P, Picton SV. Renal medullary carcinoma: Prolonged remission with chemotherapy, immunohistochemical characterization and evidence of bcr/abl rearrangement. Med Pediatr Oncol 1999;33:551-557.

4. Vargas-Gonzaiez R, Sotelo-Avila C, Coria AS. Renal medullary carcinoma in a six-year-old boy with sickle cell trait. Pathol Oncol Res 2003;9:193-195.

5. Avery RA, Harris JE, Davis CJ, Borgaonkar DS, Byrd JC, Weiss RB. Renal medullary carcinoma: clinical and therapeutic aspects of a newly described tumor. Cancer 1996;78:128-132.

6. Adsay NV, deRoux SJ, Sakr W, Grignon D. Cancer as a marker of genetic medical disease: An unusual case of medullary carcinoma of the kidney. Am J Surg Pathol 1998;22:260-264.

7. Swartz MA, Karth J, Schneider DT, Rodriguez R, Beckwith JB, Perlman EJ. Renal medullary carcinoma: Clinical, pathologic, immunohistochemical, and genetic analysis with pathologic implications. Urology 2002;60:1083-1089.

8. Hoenig JD, Husain AN, Waters BW. Pathologic quiz case. Arch Pathol Lab Med 2001;126:627-629.
9. Mathur SC, Schwartz AM. Pathologic quiz case. Arch Pathol Lab Med 2000;124:1561-1563.

10. Dimashkieh H, Choe J, Mutema G. Renal medullary carcinoma: A report of 2 cases and review of the literature. Arch Pathol lab Med 2003; 127:e135-e138.

11. Larson DM, Manson CW, Henry MR. Renal medullary carcinoma: Report of a case with positive urinary cytology. Diagn Cytopathol 1998;18:276-279.

12. Assad L, Resetkova E, Oliveira VL, et al. Cytologic features of renal medullary carcinoma. A study of three cases Cancer (Cancer Cytopathol) 2005;105:28-34.

13. Qi J, Shen PU, Rezuke WN, Currier AA, Westfall PK, Mandavilli SR. Fine needle aspiration cytology diagnosis of renal medullary carcinoma: A case report. Acta Cytol 2001;45:735-739.

14. French CA. Respiratory tract. In: Cibas ES, Ducatman BS, editors. Cytology: Diagnostic principles and clinical correlates. 2nd ed. London: Saunders; 2003 p 80-82.

15. Murphy WM, Zambroni BR, Emerson LD, Moinuddin S, Lee LH. Aspiration biopsy of the kidney. Cancer 1985;56:200-205.

16. Powers CN, Elbadawi A. "Cercariform" cells: A clue to the cytodiagnosis of transitional cell origin of metastatic neoplasms? Diagn Cytopathol 1995;13:15-21.

17. Caraway NP, Wojcik EM, Katz RL, Ro JY, Ordonez NG. Cytologic findings of collecting duct carcinoma of the kidney. Diagn Cytopathol 1995;13:304-309.

18. Srigley JR, Eble JN. Collecting duct carcinoma of the kidney. Semin Diagn Pathol 1998;15:54-67.

19. Akhtar M, Iqbal MA, Mourad W, Ali MA. Fine-needle aspiration biopsy diagnosis of small round cell tumors of childhood: A comprehensive approach. Diagn Cytopathol 1999;21:81-91.

20. Akhtar M, Ali MA, Sackey K, Bakry M, Burgess A. Fine-needle aspiration biopsy diagnosis of malignant rhabdoid tumor the kidney. Diagn Cytopathol 1991;7:36-40.

21. Yang XY, Sugimura J, Tretiakova MS, et al. Gene expression profiling of renal medullary carcinoma. Cancer 2004;100:976985.

22. Cheng JX, Tretiakova M, Gong C, Mandal S, Krausz T, Taxy JB. Renal medullary carcinoma: rhabdoid features and the absence of INI1 expression as markers of aggressive behavior. Mod Pathol 2008;21:647-652. 